\section{AN UNUSUAL CASE OF MESENTERIC TRANSPLANTATION}

\author{
VICENTE CASTRO, M.D. (Belgium) \\ SAN JOSE, COSTA RICA
}

At operation a case will occasionally be encountered in which the ordinary methods of covering peritoneal defects prove unsuitable. Therefore a further practical experience should prove of interest to the profession. Even in the largest surgical clinic with which I am acquainted, the Eppendorfer Krankenhaus in Hamburg, Germany, during my three years' work there as assistant, no case presented itself in which the method to be described seemed indicated, nor have I seen one anywhere else.

In 1876 Tietze, ${ }^{1}$ advised the use of omental grafts to reinforce end to end entero-anastomoses, to close small wounds on the stomach surface, and to cover necrotic patches which he had experimentally produced on the surface of the intestines.

Senn $^{2}$ in 1888 recorded his experiments showing that grafts of omentum applied to the bowel may retain their vitality, becoming adherent within eighteen hours, and are nourished with newly formed blood vessels within forty-eight hours.

Ammann, ${ }^{3}$ I believe, also recommends the use of omental grafts for the same purpose. From experimental evidence he is convinced that almost any part of the peritoneum may be used in covering peritoneal defects. He advises the use of the sigmoid to close the open space between Douglas' sac and the bladder after hysterectomy whenever a simpler method of closure is not feasible.

A study of the literature shows that there are many suitable cases for the use of omental grafts and that although substantial differences of opinion prevail among authors concerning the danger of the formation of adhesions between the grafted organ and the adjacent peritoneal surface, the graft is generally considered a valuable means of protecting the abdominal cavity from intestinal leakage in cases in which an ideal Lembert suture cannot be made. Among the many articles on this general subject I have found no mention of the method to be described, and which seemed to me a valuable aid in an unusual and trying case.

REPORT OF CASE

History.-The patient was a single woman aged 35 , whose chief complaint was a severe, chronic constipation. All symptoms seemed to be dependent on this trouble. She had had tenderness in the right iliac fossa for several years and several slight attacks of appendicitis. Through the very thick abdominal wall nothing definite could be palpated. The constipation was often accompanied by pain and tympanites. There was general lassitude with rapid and feeble heart action. Heart sounds were not clear, but there were no definite murmurs, though since childhood she had had severe attacks of rheumatic fever. There was a chronic bronchitis. Because of metrorrhagia she was operated on four years previously for a multiple uterine fibroid. Since then menstruation had been late and the flow scanty. The conditions to be described were probably overlooked at the former operation. Although the removal of the appendix had been advised, it was not removed because of the patient's bad condition during anesthesia.

Opcration.-The abdomen was opened by a median hypogastric incision in the scar of the former operation. The

1. Tietze: Beitr. z. klin. Chir., 1876.

2. Senn, N.: Ann. Surg., 1888. cecum and proximal colon were not movable. The omentum was irregularly thickened and adherent to the abdominal wall and intestines. After prolonged search the appendix was found imbedded in a mass of omental and intestinal adhesions. It was excised with ligation and cauterization of the stump, an invagination not being feasible. On further search a very thick adhesion was encountered between the ileum and peritoneum over the right sacro-iliac synchondrosis and another one between two loops of small intestine. Finally, a Meckel's diverticulum was found attached to the free border of the ileum, with evident signs of chronic inflammation of its terminal portion yet floating free in the abdominal cavity.

The diverticulum was about three times as large as the normal appendix, with a very slight constriction at its intestinal attachment. It was determined to remove it as one would an appendix, so after clamping and ligating in the usual way, the stump was invaginated with a purse-string suture. When this was tied, it was found seriously to diminish the intestinal lumen so that an obstruction was to be feared. To avoid this complication, the purse-string suture was cut off and to cover the tump and the raw surface produced by the suture, I dissected ${ }^{-}$a piece of the mesentery between two veins as large as a silver half dollar. This was sutured around its border with interrupted sutures covering the denuded area on the bowel, and so placed that the raw surface of the transplant was in contact with the defect on the intestine. A few sutures united the edges of the denuded area on the mesentery. The operation had then to be terminated because the patient's general condition had been bad throughout the anesthesia. The abdomen was closed without drainage. There was a slight rise of temperature following the operation, but nothing otherwise unusual throughout the following week. Bowels were moved on the third day with a saline cathartic. Recovery was uneventful and the patient was out of bed on the twelfth day.

I wish to emphasize that my method of covering the raw surface was quite different from the two usual methods, that is, suture of omentum to raw surface, and second, torsion of the gut on its long axis with suture to an attached flap of the mesentery. Both methods seemed to me liable to produce adhesions of this segment of gut in a patient in whom already the peritoneal surfaces were much altered and organs fixed. It seemed to me that a transplant rather than a flap of mesentery would offer the best method of surmounting the technical difficulties, and the postoperative course of the patient has confirmed this conclusion.

Let me add further that when I performed this operation I was not familiar with the work of the authors previously mentioned. I was, however, familiar with Tuffier's work on ovarian transplantation and Carrel's work on transplantation of the kidney in a dog.

The country in which I live is the smallest of American republics and is at the beginning both of its general and scientific development, and is distant from any medical center, so that medical and surgical progress must be rather slow for a time, at least. I hope that this case of successful transplantation of mesentery may be considered worthy of publication.

Sewage Disposal.-The Arkansas supreme court recently rendered a decision in a suit for damages for injury to property by the presence of a septic tank and drainage from it, which. polluted a stream flowing through the plaintiff's land. The court held that the sewer district was liable for the amount by which the value of the plaintiff's land was depreciated by reason of the construction and operation of the septic tank, but that no damage could be recovered because of the acts of employees of the municipality in unnecessarily flushing the tank.-Public Health Reports. 